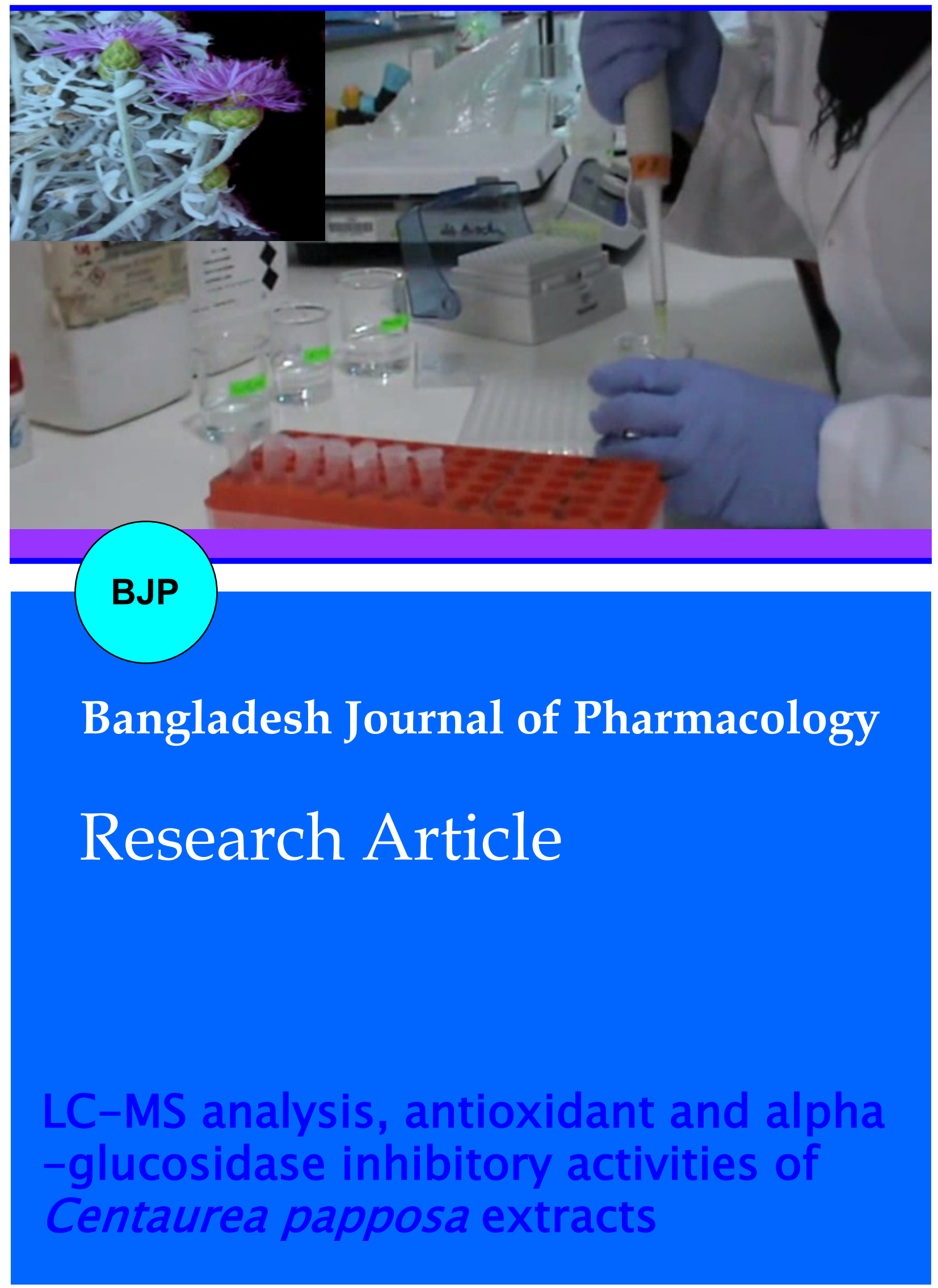




\title{
LC-MS analysis, antioxidant and alpha-glucosidase inhibitory activities of Centaurea papposa extracts
}

\author{
Cheribet Mawahib', Zaabat Nabila', Souilah Nabila1, Bensouici Chawki ${ }^{2}$ and Akkal Salah'1
}

${ }^{1}$ Valorization of Natural Resources, Bioactive Molecules and Biological Analysis Unit, Department of Chemistry, University of Mentouri Constantine, Constantine 25000, Algeria; ${ }^{2}$ Laboratory of Biochemistry, Biotechnology and Health Division, Center for Research in Biotechnology, Constantine 25000, Algeria.

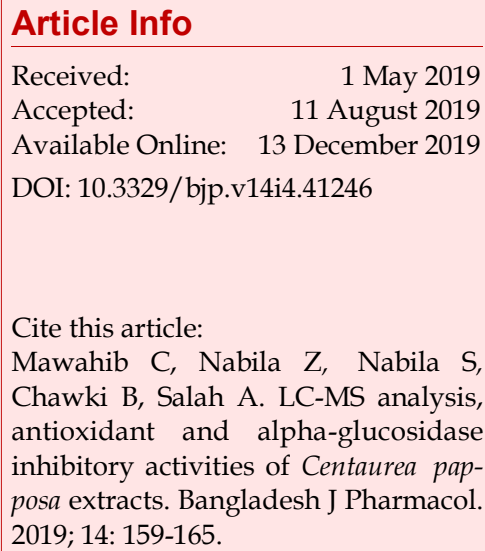

\section{Abstract}

This work aimed to ascertain the phenolic compounds and assess the antioxidant capacity and alpha-glucosidase inhibitory activity of Centaurea papposa extracts. Phenolic compounds were appraised using LC-MS technique. Moreover, antioxidant activity was investigated using DPPH, ABTS, CUPRAC and FRAP assays. In vitro alpha-glucosidase inhibitory effect was carried out. LC-MS analysis revealed the presence of 21 compounds among which 13 were phenolic acids, 6 flavonoids, 1 phenolic aldehyde and 1 benzopyrone. The ethyl acetate extract exhibited the highest activity in ferric reducing antioxidant power (FRAP) assay $\left(\mathrm{IC}_{50}: 22.9 \pm 2.8 \mu \mathrm{g} / \mathrm{mL}\right.$ ). Nevertheless the $n$-butanol extract was the most active in cupric reducing antioxidant capacity assay $\left(\mathrm{IC}_{50}: 3.1 \pm 0.1 \mu \mathrm{g} / \mathrm{mL}\right)$. A significant alpha-glucosidase inhibitory activity was displayed by dichloromethane extract $\left(\mathrm{IC}_{50}: 227.6 \pm 4.4\right.$ $\mu \mathrm{g} / \mathrm{mL})$

\section{Introduction}

Diabetes mellitus is a chronic disease of metabolic disorder (Pallavi et al., 2015) which is treated by either insulin or oral anti-diabetic drugs. Among the oral antidiabetic drugs, alpha-glucosidase inhibitor retards the liberation of d-glucose from dietary complex carbohydrates and delays glucose absorption, resulting in reduced postprandial plasma glucose level and suppession of postprandial hyperglycemia. Plants such as Camellia sinensis (Hara and Honda, 1992), Ipomoea batatas (Matsui et al., 1996), berry (McDougall and Stewart, 2005), Syzygium zeylanicum, Cleistocalyx operculatus, Horsfieldia amygdalina and Careya arborea (Truong et al., 2007) show alpha-glucosidase inhibitor activity.

The genus Centaurea L. (Asteraceae, Carduae) is characterized by biosynthesis of sesquiterpene lactones (Medjroubi et al., 1998) and flavonoids (Akkal et al., 2003). They have long been used in traditional medicine to treat fever, diabetes and hemorrhoid and peptid ulcer (Honda et al., 1996; Karg1oğlu et al., 2008). Centa- urea papposa is a species belonging to the Centaurea section, subsection Acrolophus (Cass.) DC (Hilpold et al., 2011), increasing wild in Algeria and Tunisia.

The chemical profile of the endemic species C. papposa of Algeria, has not been reported before. For this reason, this plant was chosen to explore its chemical compounds and quantities of the phenolic compounds by LC-MS/MS and to evaluate the $\alpha$-glucosidase inhibitory activities and antioxidants in vitro by different methods.

\section{Materials and Methods \\ Chemicals used}

For LC-MS/MS analysis: The analytical standards of quinic acid, malic acid, fumaric acid, gallic acid, protocatechic acid, pyrocatechol, chlorogenic acid, 4-OHbenzoic acid, vanillic acid, caffeic acid, syringic acid, vanillin, salicylic acid, $p$-coumaric acid, rutin, ferulic 
acid, sinapic acid, hesperidin, isoquercitrin, rosmarinic acid, nicotiflorin, a-coumaric acid, rhoifolin, quercitrin, apigetrin, coumarin, myricetin, fisetin, cinnamic acid, liquiritigenin, quercetin, luteolin, naringenin, apigenin, hesperetin, kaempferol and chrysin were purchased from Sigma-Aldrich, Italy. HPLC-grade acetonitrile, ammonium formate and formic acid were purchased from Sigma-Aldrich, Italy.

For extracts and biological activities: Quercetin, potassium persulfate, ferrous chloride, dichloromethane, ethyl acetate, n-butanol, a-tocopherol, acarbose and ethylenediamine tetraacetic acid (EDTA) were obtained from E. Merck, Germany. Folin-Ciocalteu's reagent (FCR), neocuproine, butylated hydroxytoluene (BHT), $\mathrm{DPPH}$ dye, sodium carbonate, aluminum chloride, phosphate buffer, ammonium acetate buffer, potassium ferricyanide, butyl hydroxyanisole (BHA), methanol and ethanol were obtained from Sigma Chemical Co., Germany. 2,20-Azinobis (3-ethylbenzothiazoline-6-sulfonic acid) diammonium salt (ABTS), p-nitrophenyl-a-D -glucopyranoside solution, alpha-glucosidase, ascorbic acid, tannic acid were obtained from Fluka Chemie, Germany.

\section{Plant material}

The aerial parts of the plant were collected in full bloom in Annaba (North East of Algeria) in September 2016. They were identified by Dr. Hamel Tarek, Department of Plant Biology and Environment, Badji Mokhtar University, Annaba, Algeria. A reference specimen was deposited in the herbarium of the laboratory under the reference code No.: ChifaDZUMCAPBC000039. The samples were dried in the shade at room temperature in a ventilated place and cut into small pieces.

\section{Preparation of extracts}

The air-dried powdered aerial parts of C. papposa (600 g) were successively macerated with dichloromethane $(6 \mathrm{~L}$ $\times 3)$ and methanol $(4 \mathrm{~L} \times 3)$ at room temperature for 24 hours. After concentration under reduced pressure, dichloromethane $(10 \mathrm{~g})$ and methanol (56 g) extracts were obtained. The methanol extract was dissolved in hot distilled water. The resulting solution was successively extracted by solvents with increasing polarity ethyl acetate and $n$-butanol evaporated under reduced pressure to obtain $2 \mathrm{~g}$ of ethyl acetate and $16 \mathrm{~g}$ of $n$ butanol extracts.

\section{LC-MS method development and validation}

The LC-MS analyses of phenolic compounds were performed using a Nexera model Shimadzu UHPLC coupled to a tandem MS instrument. The liquid chromatography was equipped with LC30AD binary pumps, CTO-10ASvp column oven, DGU-20A3R degasser and SIL-30AC autosampler. The chromatographic separation was performed on an RP-C18 Inertsil ODS-4 (100 $\mathrm{mm} \times 2.1 \mathrm{~mm}, 2 \mu \mathrm{m})$ analytical column. Reversed- phase ultrahigh performance liquid chromatography was optimized to achieve optimum separation for 37 phytochemical compounds and to overcome the suppression effects. The column temperature was fixed at $35^{\circ} \mathrm{C}$. The elution gradient consisted of eluent $\mathrm{A}$ (water, $10 \mathrm{mM}$ ammonium formate and $0.1 \%$ formic acid) and eluent $B$ (acetonitrile). The following gradient elution program was applied: $5-20 \%$ B (0-10 $\mathrm{min}), 20 \%$ B (10-22 min), 20-50\% B (22-36 min), 95\% B (36-40 min), $5 \%$ B (40-50 min). The solvent flow rate was maintained at $0.25 \mathrm{~mL} / \mathrm{min}$ and the injection volume was settled as $4 \mu \mathrm{L}$.

MS detection was performed using a Shimadzu brand. LCMS 8040 model tandem mass spectrometer equipped with an ESI source operating in negative ion mode. LCESI-MS/MS data were collected and shipped by LabSolutions Software (Shimadzu) software. Multiple reaction monitoring (MRM) was used to quantify it. The working conditions of the mass spectrometer were passed as interface temperature, $350^{\circ} \mathrm{C}$; DL temperature, $250^{\circ} \mathrm{C}$; temperature of the thermal block, $400^{\circ} \mathrm{C}$; nebulization gas flow (nitrogen), 3L/min; and drying gas stream (nitrogen), $15 \mathrm{~L} / \mathrm{min}$.

A complete LC-MS/MS method was optimized and validated for the quantification of 37 phytochemical fingerprint compounds (17 flavonoids, 15 phenolic acids, 3 non-phenolic organic acids, 1 benzopyrene and 1 phenolic aldehyde) on the species studied. The performance characteristics of the method were determined using standard solutions, enriched and nonenriched samples. In this context, the developed method has been fully validated in terms of linearity, accuracy (recovery), interday and intraday precision (repeatability), detection and quantification limits (LOD/LOQ) and uncertainty relative standards (U\% at 95\% confidence level $[\mathrm{k}=2]$ ) (Table I).

\section{Determination of antioxidant activity \\ DPPH radical scavenging assay}

DPPH assays based on measurement of the scavenging capacity of antioxidants towards a stable free radical $a$, a-diphenyl- $\beta$-picrylhydrazyl (DPPH; C18H12N5O6, $\mathrm{M}=394.33$ ). The odd electron of the nitrogen atom in DPPH was reduced by receiving a hydrogen atom from antioxidants to the corresponding hydrazine (Kedare and Singh, 2011).

The antiradical activity of crude extracts obtained from the species C. papposa was evaluated by the free radical DPPH assay (Blois, 1958). A solution of $40 \mu \mathrm{L}$ of the sample (extract or standard) at different dilutions was completed with $160 \mu \mathrm{L}$ of the DPPH methanol solution $(0.1 \mathrm{mM})$. DPPH reagent in methanol was used as a blank. After $31 \mathrm{~min}$, the absorbance of each solution was detected at $517 \mathrm{~nm}$ using a microplate reader. Butyl hydroxyl toluene (BHT) and butyl hydroxyanisole (BHA) were used as positive controls. The percentage of 
radical scavenging activity was calculated as follows:

$\%$ Inhibition $=\left[\left(\mathrm{A}_{\text {control }}-\mathrm{A}_{\text {sample }}\right) / \mathrm{A}_{\text {control }}\right] \times 100$

Where, $\mathrm{A}_{\text {control }}$ is the absorbance of control reaction (containing all reagents except the test extract or standard), and $A_{\text {sample }}$ is the absorbance of the test extract or standard

The result was expressed as $\mathrm{IC}_{50}$ value $(\mu \mathrm{g} / \mathrm{mL})$ corresponding of sample concentration that inhibits 50\% $\mathrm{DPPH}$ of free radical.

\section{ABTS radical scavenging assay}

The ABTS antioxidant assay measures ABTS+ $\bullet$ radical production induced by potassium persulfate.

The ABTS scavenging activity was determined according to the method described earlier (Re et al., 1999). $\mathrm{ABTS}^{+}$was produced by the reaction between $7 \mathrm{mM}$ of ABTS in water and $2.45 \mathrm{mM}$ potassium persulfate, stored in the dark at room temperature for 12 hours before use. ABTS ${ }^{+}$solution was then diluted with methanol to obtain an absorbance of $0.70 \pm 0.02$ at 734 $\mathrm{nm}$. After the addition of $160 \mu \mathrm{L}$ of diluted ABTS + to $40 \mu \mathrm{L}$ of diffèrent concentrations of crude extracts and standards (BHT, BHA), the absorbance was measured at $734 \mathrm{~nm}$ after $10 \mathrm{~min}$ of the initial mixing using a 96well microplate reader. The scavenging activity of $\mathrm{ABTS}^{+}$radical was expressed as the inhibition percentage using the following equation:

$\%$ Inhibition $=\left[\left(\mathrm{A}_{\text {control}}-\mathrm{A}_{\text {sample }}\right) / \mathrm{A}_{\text {control }}\right] \times 100$

Where, $\mathrm{A}_{\text {control }}$ is control absorbance reaction (containing all reagents except the test extract or standard), and $\mathrm{A}_{\text {sample }}$ is the absorbance of extract or standard

\section{Reducing power assay (FRAP)}

FRAP assay measures the change in absorbance at 593 $\mathrm{nm}$ which indicated with the appearance blue colored $\mathrm{Fe}^{2+}$-tripyridyltriazine compound from colorless oxidized $\mathrm{Fe}^{3+}$ form by the action of electron donating antioxi-

\section{Box 1: Cupric reducing antioxidant capacity}

\section{Principle}

The cupric ion reducing antioxidant capacity (CUPRAC assay) evaluates the capacity of antioxidants to reduce the $\mathrm{Cu}^{2+}$ to $\mathrm{Cu}^{+}$in the presence of a chelating agent. It is efficient for glutathione and thiol-type antioxidants, for which the FRAP test is nonresponsive.

\section{Requirements}

Ammonium acetate buffer; $\mathrm{Cu}$ (II) solution; Extract; Neocuproine; UV-Vis spectrophotometer

\section{Procedure}

Step 1: Ammonium acetate buffer $(60 \mu \mathrm{L} ; 1 \mathrm{M}, \mathrm{pH} 7.0)$ solution, neocuproine solution $(50 \mu \mathrm{L} ; 7.5 \mathrm{mM})$ and $\mathrm{Cu}$ (II) solution $(50 \mu \mathrm{L}, 10 \mathrm{mM})$ were added to a test tube. dants (Popova et al., 2014).

The FRAP of the crude extract was determined according to the method described earlier (Marco, 1968). In which, $10 \mu \mathrm{L}$ of different concentrations of extracts were mixed with $40 \mu \mathrm{L}$ of phosphate buffer $(0.2 \mathrm{M}, \mathrm{pH}$ 6.6) and $50 \mu \mathrm{L}$ of potassium ferricyanide $(10 \mathrm{mg} / \mathrm{mL})$. Then, the reaction mixture was incubated at $50^{\circ} \mathrm{C}$ for 20 min, after that the reaction mixture was acidified with $50 \mu \mathrm{L}$ of trichloroacetic acid solution $(10 \%)$, and $10 \mu \mathrm{L}$ of ferric chloride solution $(0.1 \%)$ was added to this solution. The absorbance was measured at $700 \mathrm{~nm}$.

\section{Alpha-glucosidase inhibitor activity}

The a-glucosidase inhibitor activity was investigated using the method described elsewhere (Lordan et al., 2013). A volume of $50 \mu \mathrm{L}$ of extract solution and $50 \mu \mathrm{L}$ of p-nitrophenyl-a-D-glucopyranoside solution $5 \mathrm{mM}$ (in phosphate buffer $100 \mathrm{mM}, \mathrm{pH}$ 6.9) were mixed and incubated at $37^{\circ} \mathrm{C}$ for $10 \mathrm{~min}$. Then, $100 \mu \mathrm{L}$ of alphaglucosidase $(0.1 \mathrm{U} / \mathrm{mL})$ was added and the absorbance was recorded at $405 \mathrm{~nm}$ after 0 and 30 min respectively. The pharmacological inhibitor, acarbose, was included as a positive control.

The activity of a-glucosidase was calculated as follows:

$\%$ Activity $=[($ Absorbance of control - Absorbance of extract)/Absorbance of control] $\times 100$

\section{Statistical analysis}

In this study, analyses were carried out in triplicate of each sample and each experiment was realized out in triplicate $(n=3)$. The mean value and standard deviation were calculated from the data obtained. Data of bioassays were the subject of one-way analysis of variance (ANOVA) using the SPSS 18.0 software (SPSS Inc.) followed by Tukey's test. The level of significance was fixed at $\mathrm{p}<0.05$.

Step 2: Mixed well using vortex mixer.

Step 3: $40 \mu \mathrm{L}$ of the sample solutions at different concentrations were added.

Step 4: Mixed well using vortex mixer.

Step 5: After $30 \mathrm{~min}$, the absorbance was read at $450 \mathrm{~nm}$ using spectrophotometer.

\section{Analysis of results}

The results were given as $0.5(\mu \mathrm{g} / \mathrm{mL})$ which corresponding to concentration indicating $50 \%$ of absorbance intensity and results were compared with those of standards BHT and BHA.

\section{References}

Apak et al., 2004; Rubio et al., 2016 


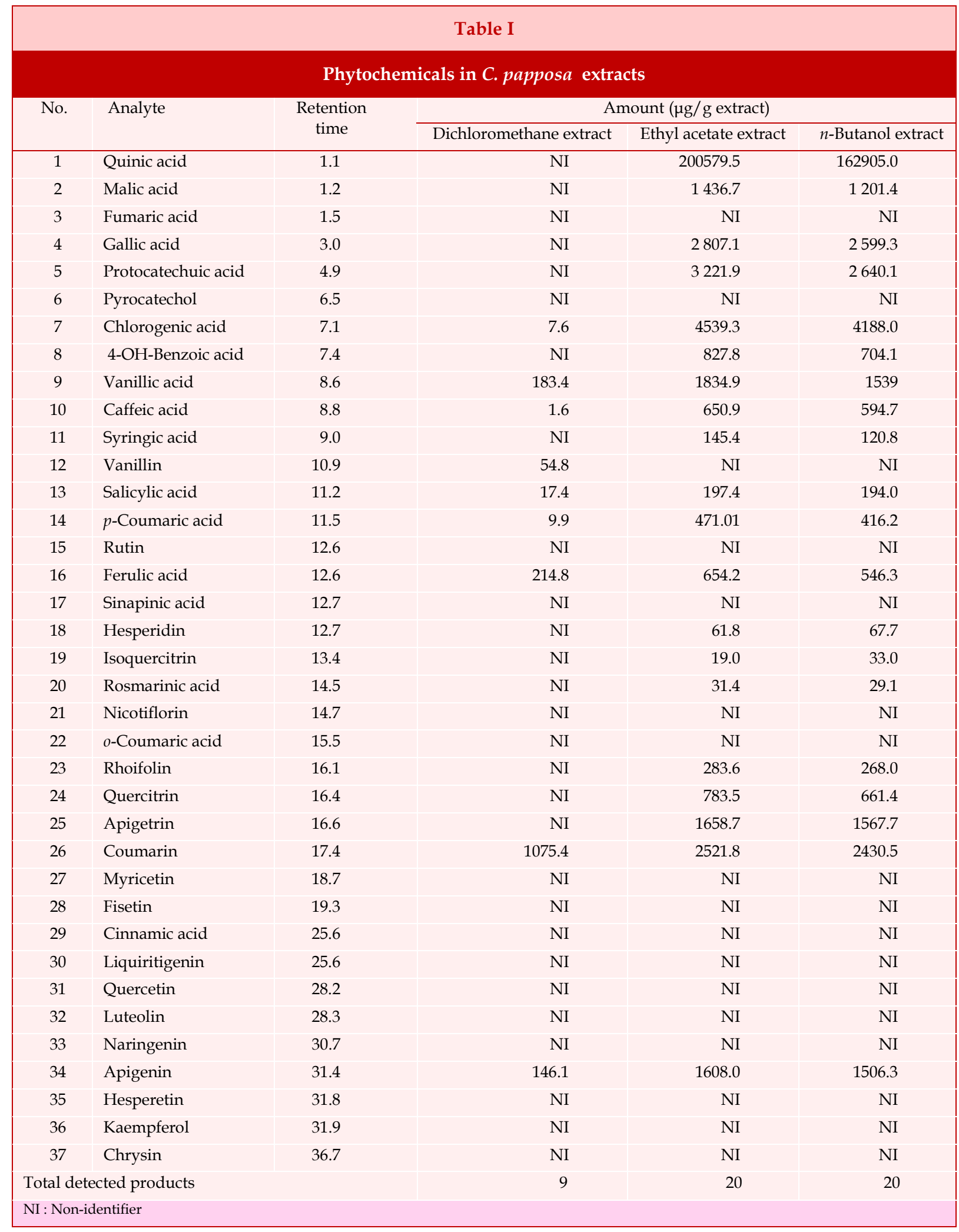

\section{Results}

\section{Identification and quantification of contents}

Following the LC-MS results, phenolic acid contents in
C. papposa extracts were higher than their of flavonoid contents (Table I). The LC-MS analysis of ethyl acetate extract revealed the presence of quinic acid, malic acid, gallic acid, protocatechuic acid, chlorogenic acid, vani- 


\begin{tabular}{|c|c|c|c|c|}
\hline \multicolumn{5}{|c|}{ Table II } \\
\hline \multicolumn{5}{|c|}{ Antioxidant activities of $C$. papposa extracts } \\
\hline Extract & $\begin{array}{r}\mathrm{DPPH} \mathrm{IC} \\
(\mu \mathrm{g} / \mathrm{mL})\end{array}$ & $\begin{array}{l}\text { ABTS IC }_{50} \\
(\mu \mathrm{g} / \mathrm{mL})\end{array}$ & $\begin{array}{c}\text { CUPRAC } \\
\text { A0.50 }(\mu \mathrm{g} / \mathrm{mL})\end{array}$ & $\begin{array}{r}\text { Reducing power } \\
\mathrm{A} 0.50(\mu \mathrm{g} / \mathrm{mL})\end{array}$ \\
\hline Dichloromethane & NA & $>100$ & $>100$ & $>200$ \\
\hline Ethyl acetate & $18.1 \pm 0.6$ & $11.7 \pm 0.2$ & $4.9 \pm 0.0$ & $22.9 \pm 2.8$ \\
\hline$n$-Butanol & $17.0 \pm 0.9$ & $22.6 \pm 1.2$ & $3.1 \pm 0.1$ & $42.1 \pm 2.9$ \\
\hline Butyl hydroxyl toluene & $6.8 \pm 0.5$ & $1.6 \pm 0.0$ & $9.6 \pm 0.9$ & NT \\
\hline Butyl hydroxyl anisole & $6.8 \pm 0.5$ & $1.0 \pm 0.0$ & $3.6 \pm 0.2$ & NT \\
\hline Ascorbic acid $(4 \mu \mathrm{g} / \mu \mathrm{L})$ & NT & NT & NT & $6.8 \pm 1.2$ \\
\hline Tannic acid $(4 \mu \mathrm{g} / \mu \mathrm{L})$ & NT & NT & NT & $5.4 \pm 0.9$ \\
\hline a-Tocopherol $(4 \mu \mathrm{g} / \mu \mathrm{L})$ & NT & NT & NT & $34.9 \pm 2.4$ \\
\hline
\end{tabular}

\begin{tabular}{|lc|}
\hline \multicolumn{2}{|c|}{ Table III } \\
\hline \multicolumn{2}{|c|}{ Alpha-glucosidase inhibitory assay of C. papposa } \\
extracts
\end{tabular}

llic acid, syringic acid, apigetrin, apigenin and coumarin showed the highest concentrations (200579.8, 1436.7, 2807.1, 3221.9, 4 539.34, 1834.9, 1658.7, 2521.8, $1608.0 \mu \mathrm{g} / \mathrm{g}$ extract) respectively. While 4-OH-benzoic acid, caffeic acid, salicylic acid, $p$-coumaric acid, ferulic acid, rosmarinic acid, hesperidin, isoquercitrin, rhoifolin and quercitrin were found with the lowest values.

On the other hand, the same previously cited phenolic compounds were detected in the $n$-butanol extract. Finally, coumarin showed the highest values (1075.4 $\mu \mathrm{g} / \mathrm{g}$ extract) followed by ferulic acid, vanillic acid, apigenin and vanillin in dichloromethane extract.

\section{Antioxidant activity}

For DPPH test, maximum scavenging activity was found in $n$-butanol extract $\left(\mathrm{IC}_{50}\right.$ value: $17.0 \pm 0.9 \mu \mathrm{g} /$ $\mathrm{mL})$, followed by ethyl acetate extract ( $\mathrm{IC}_{50}$ value: $18.1 \pm$ $0.6 \mu \mathrm{g} / \mathrm{mL}$ ). Dichloromethane extract was inactive. In the ABTS method, the ethyl acetate extract exhibited the highest activity ( $\mathrm{IC}_{50}$ value: $11.7 \pm 0.2 \mu \mathrm{g} / \mathrm{mL}$ ) among all extracts, followed by $n$-butanol ( $\mathrm{IC}_{50}$ value: $22.6 \pm 1.2$ $\mu \mathrm{g} / \mathrm{mL})$. Results of CUPRAC of extracts were compared with those of BHA and BHT (Table II). Activity (absorbance) increased linearly with the increasing of extract amount. $n$-Butanol extract exhibited the highest activity, it was better than those of standards $\left(\mathrm{A}_{0.50}\right.$ value: $3.1 \pm 0.1 \mu \mathrm{g} / \mathrm{mL}$ ). Ethyl acetate extract indicated the higher activity, it was better than that of BHT, but lower than the BHA $(4.9 \pm 0.0 \mu \mathrm{g} / \mathrm{mL})$. Ethyl acetate extract exhibited higher ferric reducing power ability than the a-tocopherol $(22.9 \pm 2.8 \mu \mathrm{g} / \mathrm{mL})$, which is adjoining to $n$-butanol extract $(42.1 \pm 2.9 \mu \mathrm{g} / \mathrm{mL})$ but this activity was relatively lower than that of ascorbic acid and tannic acid (Table II).

\section{Alpha-glucosidase inhibitor activity}

Dichloromethane extract showed a greater inhibition activity compared to acarbose $\left(\mathrm{IC}_{50}\right.$ value: $227.6 \pm 4.4$ $\mu \mathrm{g} / \mathrm{mL}$ ). Ethyl acetate extract ( $\mathrm{IC}_{50}$ value: $791.9 \pm 1.8$ $\mu \mathrm{g} / \mathrm{mL}$ ) exhibited weak inhibitory activity against alpha-glucosidase. The $n$-butanol extract, however, was inactive (Table III).

\section{Discussion}

Biological potential and total phenolic contents of $C$. papposa are reported for the first time in this work. The LC-MS/MS analysis of C. papposa extracts revealed the presence of 21 phenolic compounds. The protocatechuic acid, chlorogenic acid, caffeic acid, syringic acid, $p$ coumaric acid, ferulic acid, coumarin, salicylic acid, vanillic acid and apigenin presented the highest values. Previous experiments on Centaurea have shown the presence of major phenolic compounds, quercetin, quercetin-3- $\beta$-D-glucoside and protocatechuic from $C$. amaena and C. aksoyi (Albayrak et al., 2017), chlorogenic, caffeic, ferulic, and $p$-coumaric acids, isoquercitrin, and coumarin from C. cyanus (Escher et al., 2018), $\beta$ sitosterol 3-glucoside, protocatechuic acid, scopoletin, chlorogenic acid, cen-taurein, kaempferol-3-glucoside, jacein, arctiin, querce-tin-3-glucoside and janerin from C. isaurica (Flamini et al., 2004). Sixteen compounds including protocatechuic acid, hexoside and ferulic acid were determined in the methanol extract of $C$. baseri using LC/MS (Kösen et al., 2016).

The ethyl acetate and n-butanol extract of C. papposa 
have the best antioxidant effect, it was more potential than other Centaurea species investigated in earlier studies from C. pulchella (Zengin et al., 2010), C. calcitrapa subsp. calcitrapa, C. ptosimopappa, C. spicata (Erol-Dayi et al., 2011), C. kurdika, C. rigida, C. amanicola, C. cheiroolopha and C. ptosimopappoides (Aktumsek et al., 2013).

A good correlation between total phenolic contents and antioxidant activity was demonstrated. Indeed, ethyl acetate and butanol which are richer with these compounds were generally significantly more actives. From literature, it has been well noted that medicinal plants with high amounts of phenols and flavonoids have potent antioxidant actions (da Silva et al., 2006; Ksouri et al., 2009; Falleh et al., 2011; Dehshiri et al., 2013).

On the other hand, the dichloromethane extract exhibits strong alpha-glucosidase inhibitory activity, the TLC profiling revealed with sulfuric vanillin that indicated the presence of terpenes (visible spots: blue, green, violet pink) might contribute to this activity (Ouattara et al., 2016).

\section{Conclusion}

A total of 21 compounds were identified of which the main constituents were flavonoids and phenolic acids. The ethyl acetate and $n$-butanol extracts of C. papposa have strong antioxidant properties in vitro. The dichloromethane extract exhibits strong alpha-glucosidase inhibitory activity, this result therefore clearly indicates the potential of this extract to manage hyperglycemia.

\section{Conflict of Interest}

The authors declare no conflicts of interest.

\section{Acknowledgement}

The authors wish to thank Algerian Ministry of Higher Education, Scientific Research for financial support.

\section{References}

Akkal S, Benayache F, Medjroubi K, Jay M, Tillequin F. Seguin E. flavonoids from Centaurea furfuracea. Biochem Systematics Ecol. 2003; 31: 641-43.

Aktumsek A, Zengin G, Guler GO, Cakmak YS, Duran A. Anti -oxidant potentials and anticholinesterase activities of methanolic and aqueous extracts of three endemic Centaurea L. species. Food Chem Toxicol. 2013; 55: 290-96.

Albayrak S, Atasagun B, Aksoy A. Comparison of phenolic components and biological activities of two Centaurea sp. obtained by three extraction techniques. Asian Pac J Trop Med. 2017; 10: 599-606.

Apak R, Güçlü K, Özyürek M, Karademir SE. Novel total antioxidant capacity index for dietary polyphenols and vitamins $\mathrm{C}$ and $\mathrm{E}$, using their cupric ion reducing capability in the presence of neocuproine: CUPRAC method. J Agric Food Chem. 2004; 52: 7970-81

Blois MS. Anti-oxidant determinations by the use of a stable free radical. Nature 1958; 181: 1199-200.

da Silva JFM, de Souza MC, Matta SR, de Andrade MR, Vidal FVN. Correlation analysis between phenolic levels of Brazilian propolis extracts and their antimicrobial and antioxidant activities. Food Chem. 2006; 99: 431-35.

Dehshiri MM, Aghamollaei H, Zarini M, Nabavi SM, Mirzaei M, Loizzo MR, Nabavi SF. Antioxidant activity of different parts of Tetrataenium lasiopetalum. Pharm Biol. 2013; 51: 108185.

Erol-Dayi Ö, Pekmez M, Bona M, Aras-Perk A, Arda N. Total phenolic contents, antioxidant activities cytotoxicity of three Centaurea Species: C. calcitrapa subsp. calcitrapa, C. ptosimopappa C. spicata. Free Radic Antioxid. 2011; 1: 31-36.

Escher GB, Santos JS, Rosso ND, Marques MB, Azevedo L, do Carmo MAV, Daguer H, Molognoni L, do Prado-Silva L, Sant'Ana AS, da Silva MC, Granato D. Chemical study, antioxidant, antihypertensive, and cytotoxic/cytoprotective activities of Centaurea cyanus L. petals aqueous extract. Food Chem Toxicol. 2018; 118: 439-53.

Flamini G, Stoppelli G, Morelli I, Ertugurl K, Dural H, Tugay O. Secondary metabolites from Centaurea isaurica from Turkey and their chemotaxonomical significance. Biochem Syst Ecol. 2004; 32: 553-57.

Falleh H, Ksouri R, Medini F, Guyot S, Abdelly C, Magné C. Anti-oxidant activity and phenolic composition of the medicinal and edible halophyte Mesembryanthemum edule L. Ind Crops Prod. 2011; 34: 1066-71.

Hara Y, Honda M. Inhibition of rat small intestinal sucrose and alpha-glucosidase activities by tea polyphenol. Biosci Biotechnol Biochem. 1992; 57: 123-24.

Hilpold A, Schönswetter P, Susanna A, Garcia-Jacas N, Vilatersana R. Evolution of the central Mediterranean Centaurea cineraria group (Asteraceae): Evidence for relatively recent, allopatric diversification following transoceanic seed dispersal. Taxon 2011; 60: 528-38.

Honda G, Yeşilada E, Tabata M, Sezik E, Fujita T, Takeda Y, Takaishi Y, Tanaka T. Traditional medicine in Turkey VI. Folk medicine in West Anatolia: Afyon, Kütahya, Denizli, Muğla, Aydin Provinces. J Ethnopharmacol. 1996; 53: 75-87.

Kargioğlu M, Cenkci S, Serteser A, Evliyaoğlu N, Konuk M, Kök MŞ, Bağcı Y. An ethnobotanical survey of Inner-West Anatolia, Turkey. Hum Ecol. 2008; 36: 763-77.

Kedare SB, Singh RP. Genesis and development of DPPH method of antioxidant assay. J Food Sci Technol. 2011; 48: 412-22.

Kösen YB, Işcan G, Göger F, Akalm G, Demirci B, Başer KHC. Chemical composition and biological activity of Centaurea baseri: New species from Turkey. Chem Biodivers. 2016; 13: 1369-79. 
Ksouri R, Falleh H, Megdiche W, Trabelsi N, Mhamdi B, Chaieb K, Bakrouf A, Magné C, Abdelly C. Antioxidant and antimicrobial activities of the edible medicinal halophyte Tamarix gallica L. and related polyphenolic constituents. Food Chem Toxicol. 2009; 47: 2083-91.

Lordan S, Smyth TJ, Soler-Vila A, Stanton C, Ross RP. The aamylase and a-glucosidase inhibitory effects of Irish seaweed extracts. Food Chem. 2013; 141: 2170-76.

Marco GJ. A rapid method for evaluation of antioxidants. J Am Oil Chem Soc. 1968; 45: 594-98.

Matsui TC, Yoshimoto C, Osajima K, Oki T, Osajima Y. In vitro survey of alpha-glucosidase inhibitory food components. Biosci Biotech Biochem. 1996; 60: 2019-22.

Medjroubi K, Benayache F, Benayache S, Akkal S, Kaabeche M, Tillequin F, Seguin E. Eudesmanolide from Centaurea granata. Phytochemistry 1998; 49: 2425-27.

McDougall GJ, Stewart D. The inhibitory effects of berry polyphenols on digestive enzymes. Biofactors 2005; 23: 189-95.

Ouattara LH, Kabran GRM, Kadja AB, Tano MB, Akhanovna J, Bekro YA. Phytochemical survey and antioxidant activity of plant extracts from Côte D'ivoire used in traditional treatment of hemorrhoids. Int J Innov Appl Stud. 2016; 15: 881-93.
Pallavi B, Chandresh V, Kanika K, Tammana T. In vitro evaluation of antidiabetic and antioxidant activity of Seabuckthorn (Hippophae rhamnoides L.). J Med Plants Res. 2015; 9: 929-32.

Popova A, Mihaylova D, Alexieva I. Study on the antioxidant activity of dried Allium bulgaricum leaves. Proc Biotech Food Technol. 2014; 53: 27-31.

Re R, Pellegrini N, Proteggente A, Pannala A, Yang M, RiceEvans C. Antioxidant activity applying an improved ABTS radical cation decolorization assay. Free Radic Biol Med. 1999; 26: 1231-37.

Rubio CP, Hernández-Ruiz J, Martinez-Subiela S, Tvarijonaviciute A, Ceron JJ. Spectrophotometric assays for total antioxidant capacity (TAC) in dog serum: An update. BMC Vet Res. 2016; 12: 166.

Troung TM, Nghiem NT, Pham GT, Nguyen VC. Alphaglucosidase inhibitory and antioxidant activities of Vietnamese edible plants and their relationships with polyphenol contents. J Nut Sci Vitaminol. 2007; 53: 267-76.

Zengin G, Cakmak YS, Guler GO, Aktumsek A. In vitro antioxidant capacities and fatty acid compositions of three Centaurea species collected from Central Anatolia region of Turkey. Food Chem Toxicol. 2010; 48: 2638-41.

\section{Author Info \\ Akkal Salah (Principal contact) \\ I e-mail: salah4dz@yahoo.fr}

